\title{
Quality of the reporting of exercise interventions in solid organ transplant recipients: a systematic review
}

\author{
Uma Raje $^{1}$ | Tyler M Saumur ${ }^{2}$ | Fernanda Pesce de Souza ${ }^{1}$ | Sunita \\ Mathur $^{3}$ | Tania Janaudis-Ferreira ${ }^{1}$
}

${ }^{1}$ School of Physical and Occupational Therapy, McGill University

${ }^{2}$ Rehabilitation Science Institute, University of Toronto

${ }^{3}$ Department of Physical Therapy, University of Toronto

\section{Correspondence}

Tania Janaudis-Ferreira

Email: tania.janaudis-ferreira@mcgill.ca

\section{Publication Date}

May ?, 2021

\section{MJM 2021 (19) 24}

https://doi.org/10.26443/mjm.v19i1.219

\section{McGill Journal of Medicine}

www.mjmmed.com

\section{(i) (2) (2)}

This work is licensed under a Creative Commons BY-NC-SA 4.0 International License.

\section{ABSTRACT}

Background: Exercise training programs must be described in detail to facilitate replication and implementation. This study aimed to evaluate the quality of exercise training program descriptions in randomized controlled trials (RCTs) involving solid organ transplant (SOT) recipients.

Methods: We evaluated 21 RCTs reporting on exercise interventions in SOT recipients that were included in a recent systematic review/meta-analysis conducted by the research team. This previous review investigated the effects of exercise training (versus no training) in adult SOT recipients. Several databases (MEDLINE, EMBASE, CINAHL, and Cochrane Central Register of Controlled Trials) were searched from inception to May 2019. Three reviewers independently rated the exercise programs for SOT using the Consensus on Exercise Reporting Template (CERT).

Results: Mean score of the CERT was 6/19. None of the RCTs described all items of the CERT. Items of crucial importance, such as adherence, whether the exercise was done individually or in a group, whether there were home program or non-exercise components, and the type and number of adverse events, were either not mentioned or not described in detail.

Conclusion: RCTs in exercise in SOT recipients did not satisfactorily report their exercise protocols, which can lead to difficulties in replication by researchers and implementation by clinicians.

\section{KEYWORDS}

Solid organ transplant, Exercise interventions, Systematic review 


\section{1 | INTRODUCTION}

Solid organ transplantation (SOT) provides a second chance of life for people with end-stage diseases of the kidney, heart, pancreas, liver, and lung, improving the quality of life of patients. (1-3) Although some recipients can return to work, enjoy recreational activities, and participate in sports after a transplant, (2, 4-6) many patients present diminished exercise capacity and low levels of physical activity. (7-10) Regular exercise training may improve fitness in these patients, however, the majority do not reach activity and exercise capacity levels observed in healthy individuals. $(2,10,11)$ As a result of reduced physical activity levels after transplantation, SOT recipients are at increased risk for cardiovascular complications, diabetes, and mortality. $(12,13)$

There are numerous studies that have examined the role of exercise training post-SOT. $(14,15)$ Our team recently conducted a systematic review and meta-analysis on the effects of exercise (aerobic exercise, resistance exercise, or a combination of both) in SOT recipients (15) and showed that exercise training post-transplant improves exercise capacity, muscle strength, and quality of life in SOT recipients. While there have been recent scientific advances in SOT rehabilitation and convincing evidence for the benefits of exercise post-transplant, $(14,15)$ the exercise programs included in published articles are generally poorly described (14) with incomplete information on volume, intensity, and progression of exercise. The lack of information on these important variables causes difficulty in interpreting and replicating SOT exercise programs. Since exercise prescription parameters have a direct influence on the training outcomes, it is imperative that they are well-defined and clearly reported to allow for interpretation, design of future research trials, implementation into clinical practice, and ultimately, the development of guidelines. $(16,17)$ A systematic evaluation of reporting quality of exercise interventions in SOT recipients has not been conducted.

Although guidelines such as the Template for Intervention Description and Replication (TIDieR) (17) and Consolidated Standards of Reporting Trials (CONSORT) (16) exist to assist authors to report their interventions with details, these guidelines are not well-tailored for exercise interventions. Specifically, these checklists do not require precise and complete information about the type of exercise intervention, dosage, intensity, frequency, and presence of a supervisor during exercise, all of which are required to fully interpret and replicate these interventions. $(16,17)$ Recently, a more specific guideline - the Consensus on Exercise Reporting Template (CERT) - has been developed to provide direction on specific items that are necessary to report replicable exercise programs. (18) These items should be reported in all studies of any exercise type, identifying that supplementary information may be required for individual studies, depending on the exercise program under study. (18)

In this systematic review, we used the CERT checklist to evaluate the quality of the exercise training program descriptions in randomized controlled trials (RCTs) involving SOT recipients. (18) By systematically evaluating the quality of intervention reporting, suggestions can be made to improve future trials and the translation of interventions into practice.

\section{2 | METHODS}

We followed the PRISMA (Preferred Reporting Items for Systematic Reviews and Meta-Analyses) guidelines (19) and used the CERT (18) to evaluate the quality of the descriptions of the exercise training programs included in the studies.

\section{1 | Search strategy}

The articles included in this review were identified in a previous systematic review on the effects of exercise in SOT recipients that was conducted by our group. (20) The search strategy was designed to identify RCTs on exercise in SOT recipients (heart, lung, kidney, liver and pancreas). An example of the search strategy is shown in Appendix 1. The following databases were used: MEDLINE, EMBASE, CINAHL and Cochrane Central Register of Controlled Trials. ClinicalTrials.gov was 
used to identify clinical trials that were under way or recently completed. All clinical literature was searched from database inception to May 1, 2019. The following keywords were used: physical activity, exercise, physical fitness, transplant, transplantation, transplanted, organ, heart, lung, liver, kidney, pancreas. Articles in English, French, Portuguese and Spanish were considered based on the investigators' comprehension. The reference lists of all primary studies included and pertinent reviews were checked for additional references. Two researchers independently screened all titles and abstracts identified by the literature searches using Covidence software. The same pair of reviewers applied the inclusion/exclusion criteria on the full text of the potentially eligible studies. Disagreements were resolved by consensus between the reviewers.

\section{2 | Study selection}

To be eligible for the original review,(20) published studies had to: 1) be RCTs examining the effects of exercise training programs in SOT recipients, 2) study adults (> 18 years) who are recipients of heart, lung, kidney, pancreas or liver transplant, 3) involve an inpatient, outpatient or home-based program that included exercise training (aerobic, resistance training, or a combination of both) at any time post-transplant, and 4) compare an exercise training program with a control group (no exercise). Studies were excluded if they were editorials, letters to the editor, or abstracts without published peer-reviewed manuscripts. For the current systematic review, we screened 29 articles that were included in the original review. (20)

\section{3 | Consensus on Exercise Reporting Template}

The Consensus on Exercise Reporting Template (CERT) is a 16 -item tool and is internationally endorsed. $(18,21)$ It was developed using the Enhancing the QUAlity and Transparency Of health Research (EQUATOR) Network methodological framework and elaborates and expands on the previously developed TIDieR checklist. (17)
Forty-nine international multidisciplinary exercise experts participated in a modified Delphi strategy to develop the template. With three rounds of online communications, 41 initial items were distilled to the final 16 items necessary to fully describe an exercise program. The template includes "7 sections or domains: what (materials); who (provider); how (delivery); where (location); when; how much (dosage); tailoring (what, how); and how well (compliance/planned and actual)." (18) Each CERT item is rated as 0 (not described or description unclear) or 1 (yes, well-described). The maximum score of the CERT is 19. As of this writing, the CERT explanation and elaboration statement has been cited 228 times.

\section{4 | Data extraction strategy}

One investigator (UR) independently extracted and entered data regarding study characteristics into a standardized data extraction form. Two investigators (TS and FP) double-checked the data to ensure consistent reporting. Three investigators (UR, TS and FP) independently applied the CERT to all of the included articles, extracted information on the description of the exercise training program and entered data into a standardized form. The independent application of the CERT checklist was done in triplicate (each article was assessed by 3 investigators). One investigator (UR) then compared the responses and disagreements were resolved by consensus with the consultation of a fourth investigator (TJF). The template was pilot tested on one article to ensure that all evaluators were interpreting the CERT in the same way.

\section{3 | RESULTS}

\section{1 | Studies screened}

In the original review, (20) 1490 articles were identified after duplicates were removed. Fifty-nine full text .pdfs were assessed for eligibility and 29 articles met the inclusion criteria. In the current study, we have included 21 articles of the 29 that had been included in the original systematic review. (20) Eight articles were excluded 
because they were second publications of original studies and therefore used the same intervention. We chose to evaluate the first published article from each of these series. The complete PRISMA diagram for the two studies is shown in Figure 1 and the characteristics of the 21 included articles are shown in Table 1.

\section{2 | Quality of exercise intervention reporting}

The average CERT score of the 21 included studies was 6 points out of 19. Table 2 outlines the scores of each study. The scores ranged from 1 to 14 . Table 3 reports on the frequency of CERT items being delineated in the included studies. Items 1 (Type of exercise equipment; $\mathrm{n}=15(71 \%)$ ) and 13 (Detailed description of the exercise intervention - for example: number of exercise repetitions/set/sessions, session duration and program duration; $n=18(86 \%))$ were the most commonly described items. Conversely, Item 8 (Detailed description of each exercise to enable replication [e.g., photographs, illustrations, video, etc.]) and 16a (Description of how adherence or fidelity to the exercise intervention is assessed) were the least described (Table 3).

\section{4 | DISCUSSION}

The main finding of our systematic review is that RCTs on exercise interventions in SOT recipients (published before the publication of CERT) are not well described. No study described all items on the CERT. Important aspects of the exercise program were not reported, such as examples of the actual exercise, progression of the exercise, or how the starting point for intensity was chosen. Because there are currently no specific guidelines on exercise intervention in SOT, clinicians and researchers are obligated to rely on individually published RCTs and systematic reviews in this field. The lack of specific information about the exercise interventions in these trials may impede the appropriate implementation of these interventions into clinical practice or research.

The authors of TIDieR, an extension of the CON-
SORT Statement, have made general recommendations for the reporting of complex interventions in clinical trials. (17) The final 16-item CERT (18) is based on the TIDieR domains and headings (17) but contains items that are specifically related to the description of an exercise protocol to help with the actual implementation.

The most well-described item related to the characteristics of the exercise protocol was Item 13: "Detailed description of the exercise intervention (e.g., number of exercise repetitions/set/sessions, session duration and program duration)". However, illustrations (or detailed written descriptions) of actual exercises to enable replication were rarely seen in the reviewed RCTs. Scientific journals have limited the number of figures allowed for publication and therefore providing illustrations of all exercises included in the study may not be feasible unless the journal offers space in an online supplement. It was also rarely mentioned in the RCTs if exercises were done individually or in a group. The descriptions of these items are important to allow clinicians and researchers to replicate the exercise program as peer support can influence outcomes. (18) Items that describe whether the exercises were generic or tailored, and how they were tailored to the individual, were included in less than half of the reviewed studies. Exercise programs can be a standardized set of exercises or they may be tailored to the individual for various reasons such as comorbidities, musculoskeletal problems, etc. A guide of decision rules for the tailoring and implementation of time points should be provided to enable researchers to administer the program. (18)

Several other important areas that may help clinicians and researchers decide to adopt a particular exercise protocol have also been poorly described. Motivation strategies and adherence were mentioned in only $16 \%$ and $28 \%$ of the articles, respectively. Information about motivation strategies can greatly help clinicians and researchers determine which strategies can be used to ensure adherence and completion rates. Furthermore, adverse events were reported in only $12 \%$ of the articles. With safety being a basic factor affecting adherence and success of exercise interventions, detailed reporting of these events is required to decide whether an 
exercise program should be undertaken. (18) In addition, whether the intervention was delivered as planned was not described in most articles. Sometimes, an intervention needs adjustments and is not delivered as planned. The level to which this occurred must be reported, as it provides an explanation for the effect or lack of effect of an intervention and can be used to inform future studies. (18)

The CERT has been used in other patient populations, such as those who are mechanically ventilated in the intensive care unit (ICU), (22) have fibromyalgia, (23) hypertension, $(24,25)$ knee osteoarthritis (26) or osteoporosis, (27), and athletes with groin injury. (28) Similar to our findings, all of these studies (22-28) concluded that exercise interventions are not well described, though most of the studies evaluated were published prior to the publication of the CERT guidelines. One systematic review (25) limited the studies evaluated to those post 2016, but these authors also found inadequate reporting for exercise interventions in pulmonary hypertension patients. Since exercise and advice to stay active is recommended for the management of many chronic conditions, (29-32) detailed descriptions of these exercise interventions are essential.

Our study has some strengths and limitations. Our review included a rigorous methodology (with an experienced librarian) and expertise of the research team in knowledge synthesis and exercise prescription in transplant patients. An important limitation is that the CERT explanation and elaboration statement was published in 2016 (18) while all studies identified in our systematic review were published during or before 2016. While we could have used the CONSORT or TIDieR checklists in our review, these guidelines are not tailored for exercise interventions. In addition, even though the CERT was not available before 2016, the evaluation of the exercise intervention reporting is still relevant. Now that the CERT has been developed, it is hoped that more authors will become acquainted with the tool and that this will lead to the improvement in the quality of reporting of exercise interventions.

\section{5 | CONCLUSION}

Despite the important role of exercise training in the management of SOT recipients, RCTs of exercise in SOT recipients did not satisfactorily report their exercise protocols. It is recommended that researchers reporting on future clinical trials describe their exercise protocols for SOT recipients in more detail to enable replication in research and facilitate implementation of these interventions in clinical practice.

\section{6 | AUTHORS' CONTRIBUTIONS}

UR, SM and TJF contributed to the design of the study. UR, TMS ad FES applied the CERT and extracted data about the exercise programs. UR extracted other relevant data, created the tables and wrote the manuscript. All authors read the manuscript, interpreted the data and provided critical feedback.

\section{REFERENCES}

1. Kugler C, Gottlieb J, Warnecke G, Schwarz A, Weissenborn K, Barg-Hock $\mathrm{H}$, et al. Health-related quality of life after solid organ transplantation: a prospective, multiorgan cohort study. Transplantation. 2013;96(3):316-23.

2. McKenzie KJ, McKenzie DC, Yoshida EM. Solid organ transplant recipients: clinical considerations in the application of exercise. British journal of sports medicine. 2015;49(2):76-8.

3. Ortega T, Deulofeu R, Salamero P, Roman A, Masnou N, Rubio S, et al. Health-related Quality of Life before and after a solid organ transplantation (kidney, liver, and lung) of four Catalonia hospitals. Transplantation proceedings. 2009;41(6):2265-7.

4. Griffin P. Exercise and sport after organ transplantation. British journal of sports medicine. 1998;32(3):194.

5. Neale J, Smith AC, Bishop NC. Effects of Exercise and Sport in Solid Organ Transplant Recipients: A Review. American journal of physical medicine \& rehabilitation. 2017;96(4):273-88.

6. Mosconi G, Angelini ML, Balzi W, Totti V, Roi GS, Cappuccilli $M$, et al. Can Solid-Organ-Transplanted Patients Perform a Cycling Marathon? Trends in Kidney Function Parameters in Comparison With Healthy Subjects. Transplantation proceedings. 2016;48(2):415-9.

7. Williams TJ, McKenna MJ. Exercise limitation following transplantation. Comprehensive Physiology. 2012;2(3):1937-79.

8. Langer D, Gosselink R, Pitta F, Burtin C, Verleden G, Dupont $\mathrm{L}$, et al. Physical activity in daily life 1 year after lung transplan- 
tation. The Journal of heart and lung transplantation : the official publication of the International Society for Heart Transplantation. 2009;28(6):572-8

9. Takahashi A, Hu SL, Bostom A. Physical Activity in Kidney Transplant Recipients: A Review. American journal of kidney diseases : the official journal of the National Kidney Foundation. 2018;72(3):433-43.

10. van Adrichem EJ, van de Zande SC, Dekker R, Verschuuren EA, Dijkstra PU, van der Schans CP. Perceived Barriers to and Facilitators of Physical Activity in Recipients of Solid Organ Transplantation, a Qualitative Study. PloS one. 2016;11(9):e0162725.

11. Gustaw T, Schoo E, Barbalinardo C, Rodrigues N, Zameni Y, Motta VN, et al. Physical activity in solid organ transplant recipients: Participation, predictors, barriers, and facilitators. Clinical transplantation. 2017;31(4).

12. Ting SM, lqbal H, Kanji $\mathrm{H}$, Hamborg T, Aldridge N, Krishnan $\mathrm{N}$, et al. Functional cardiovascular reserve predicts survival pre-kidney and post-kidney transplantation. Journal of the American Society of Nephrology : JASN. 2014;25(1):187-95.

13. Zelle DM, Corpeleijn E, Stolk RP, de Greef MH, Gans RO, van der Heide JJ, et al. Low physical activity and risk of cardiovascular and all-cause mortality in renal transplant recipients. Clinical journal of the American Society of Nephrology : CJASN. 2011;6(4):898-905.

14. Didsbury M, McGee RG, Tong A, Craig JC, Chapman JR, Chadban $\mathrm{S}$, et al. Exercise training in solid organ transplant recipients: A systematic review and meta-analysis. Transplantation. 2013;95(5):679-87.

15. Janaudis-Ferreira T, Mathur S, Deliva R, Howes N, Patterson C, Rakel A, et al. Exercise for Solid Organ Transplant Candidates and Recipients: A Joint Position Statement of the Canadian Society of Transplantation and CAN-RESTORE. Transplantation. 2019;103(9):e220-e38.

16. Moher D, Hopewell S, Schulz KF, Montori V, Gotzsche PC, Devereaux PJ, et al. CONSORT 2010 explanation and elaboration: updated guidelines for reporting parallel group randomised trials. BMJ (Clinical research ed). 2010;340:c869.

17. Hoffmann TC, Glasziou PP, Boutron I, Milne R, Perera R, Moher $D$, et al. Better reporting of interventions: template for intervention description and replication (TIDieR) checklist and guide. BMJ (Clinical research ed). 2014;348:g1687.

18. Slade SC, Dionne CE, Underwood M, Buchbinder R. Consensus on Exercise Reporting Template (CERT): Explanation and Elaboration Statement. British journal of sports medicine. 2016;50(23):1428-37.

19. Liberati A, Altman DG, Tetzlaff J, Mulrow C, Gøtzsche PC, loannidis JP, et al. The PRISMA statement for reporting systematic reviews and meta-analyses of studies that evaluate health care interventions: explanation and elaboration. Annals of internal medicine. 2009;151(4):W-65-W-94.

20. Janaudis-Ferreira T, Tansey CM, Mathur S, Maia N, BlydtHansen T, Räkel A, Bussières, Ahmed S, Boruff J. Exercise training among solid organ transplant recipients: a systematic review and meta-analysis. Transplant International, 2021; Feb 20:online ahead of print.

21. Slade SC, Dionne CE, Underwood M, et al. Standardised method for reporting exercise programs: protocol for a modified Delphi study. BMJ Open 2014;4: e006682.

22. de Queiroz RS, Saquetto MB, Martinez BP, Andrade EA, da Silva P, Gomes-Neto M. Evaluation of the description of active mobilisation protocols for mechanically ventilated patients in the intensive care unit: A systematic review of randomized controlled trials. Heart \& lung : the journal of critical care. 2018;47(3):253-60.

23. Jo D, Del Bel MJ, McEwen D, O'Neil J, Mac Kiddie OS, Alvarez-Gallardo IC, et al. A study of the description of exercise programs evaluated in randomized controlled trials involving people with fibromyalgia using different reporting tools, and validity of the tools related to pain relief. Clinical rehabilitation. 2018:269215518815931.

24. Hacke C, Nunan D, Weisser B. Do Exercise Trials for Hypertension Adequately Report Interventions? A Reporting Quality Study. International journal of sports medicine. 2018;39(12):902-8.

25. McGregor G, Powell R, Finnegan S, Nichols S, Underwood M. Exercise rehabilitation programmes for pulmonary hypertension: a systematic review of intervention components and reporting quality. BMJ open sport \& exercise medicine. 2018;4(1):e000400.

26. Bartholdy C, Nielsen SM, Warming S, Hunter DJ, Christensen R, Henriksen M. Poor replicability of recommended exercise interventions for knee osteoarthritis: a descriptive analysis of evidence informing current guidelines and recommendations. Osteoarthritis and cartilage. 2019;27(1):3-22.

27. Mack DE, Wilson PM, Santos E, Brooks K. Standards of reporting: the use of CONSORT PRO and CERT in individuals living with osteoporosis. Osteoporosis international : a journal established as result of cooperation between the European Foundation for Osteoporosis and the National Osteoporosis Foundation of the USA. 2018;29(2):305-13.

28. Charlton PC, Drew MK, Mentiplay BF, Grimaldi A, Clark RA. Exercise Interventions for the Prevention and Treatment of Groin Pain and Injury in Athletes: A Critical and Systematic Review. Sports medicine (Auckland, NZ). 2017;47(10):2011-26.

29. Kujala UM. Evidence on the effects of exercise therapy in the treatment of chronic disease. British journal of sports medicine. 2009;43(8):550-5.

30. Smidt N, de Vet HC, Bouter LM, Dekker J, Arendzen JH, de Bie RA, et al. Effectiveness of exercise therapy: a best-evidence summary of systematic reviews. The Australian journal of physiotherapy. 2005;51(2):71-85.

31. Garber CE, Blissmer B, Deschenes MR, Franklin BA, Lamonte MJ, Lee IM, et al. American College of Sports Medicine position stand. Quantity and quality of exercise for developing and maintaining cardiorespiratory, musculoskeletal, and neuromotor fitness in apparently healthy adults: guidance for prescribing exercise. 
Medicine and science in sports and exercise. 2011;43(7):1334-59.

32. Medicine ACoS. American College of Sports Medicine position stand. Progression models in resistance training for healthy adults. Medicine and science in sports and exercise. 2009;41(3):687-708. 


\section{7 | TABLES \& FIGURES}

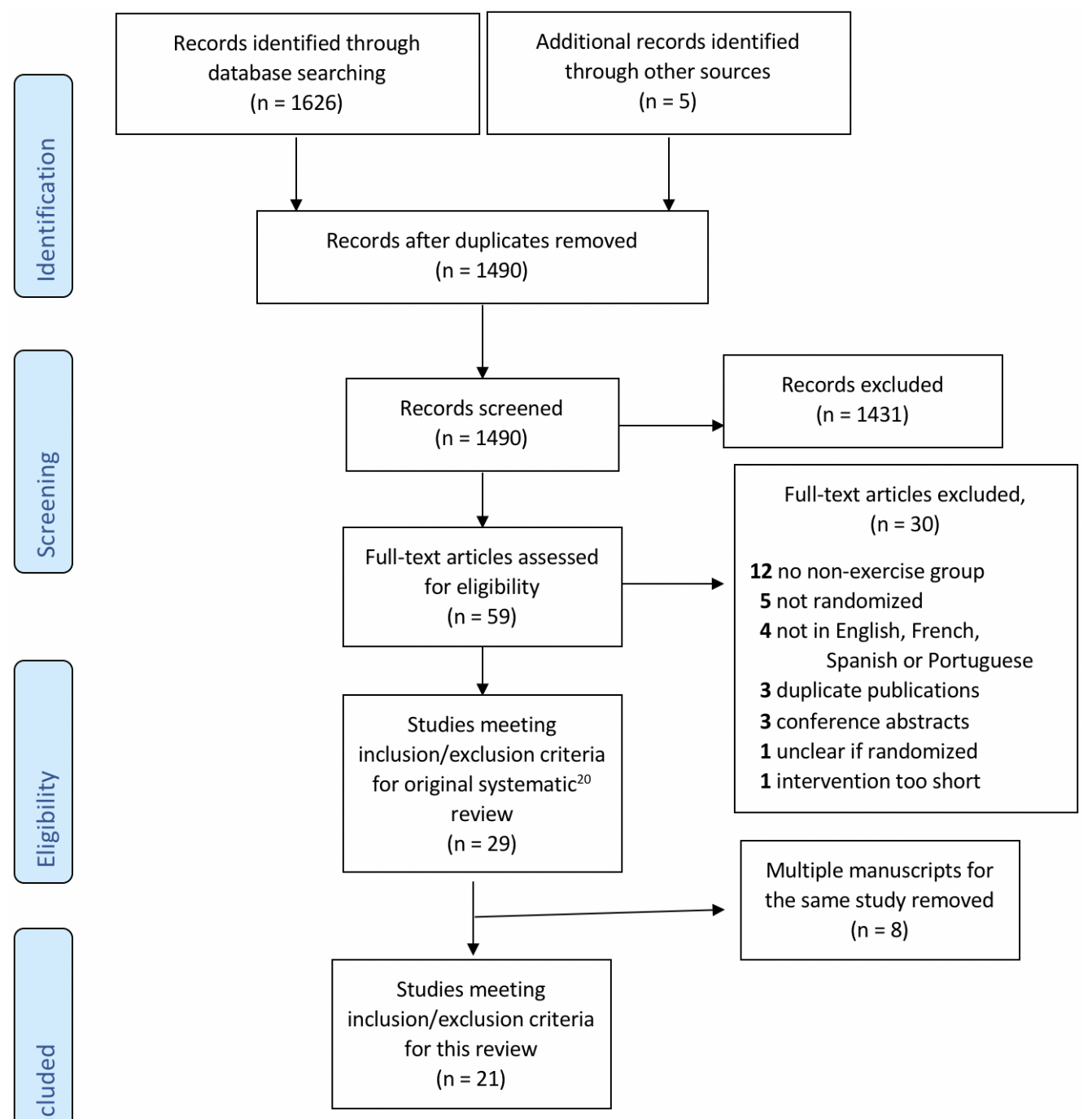

FIGURE 1 PRISMA Flow Diagram 


\begin{tabular}{|c|c|c|c|c|c|}
\hline Author \& year & Country & Organ type & Type of exercise & Training load & Program duration \\
\hline Basha et al. (2015) & Egypt & Liver & $\begin{array}{l}\text { Aerobic \& resisted } \\
\text { exercise }\end{array}$ & $\begin{array}{l}\text { Three sets of } 8-12 \text { repetitions performed at } 85 \% \\
\text { of initial } 1-R M \text {, intensity of less than } 50 \% \text { of } H R \\
\text { max. }\end{array}$ & 12 weeks \\
\hline Bernadi et al. (2007) & Italy & Heart & Aerobic & $\begin{array}{l}\text { Exercise at } 50 \mathrm{rpm} \text { for } 30 \mathrm{~min}, 5 \text { days a week at } \\
60-70 \% \text { of their peak oxygen consumption. }\end{array}$ & 6 months \\
\hline Braith et al. (2008) & USA & Heart & Aerobic & $\begin{array}{l}\text { Exercised } 3 \text { days per week. } 35-40 \text { minutes of } \\
\text { exercise as tolerated. }\end{array}$ & 12 weeks \\
\hline $\begin{array}{l}\text { Eatemadololama et } \\
\text { al. (2017) }\end{array}$ & Iran & Kidney & $\begin{array}{l}\text { Resistance } \\
\text { training }\end{array}$ & $\begin{array}{l}\text { Exercise training } 2 \text { days per week. Single set of } \\
10-15 \text { repetitions. Resistance increased by } 5-10 \\
\% \text { next sessions. }\end{array}$ & 12 weeks \\
\hline $\begin{array}{l}\text { Greenwood et al. } \\
\text { (2015) }\end{array}$ & UK & Kidney & $\begin{array}{l}\text { Aerobic or } \\
\text { resistance training }\end{array}$ & $\begin{array}{l}\text { Started with } 1-2 \text { sets and } 10 \text { repetitions (based on } \\
80 \% \text { one repetition maximum and on tolerance) } \\
\text { increasing to } 3 \text { sets and } 8-10 \text { repetitions. }\end{array}$ & 12 weeks \\
\hline $\begin{array}{l}\text { Haykowsky et al. } \\
(2009)\end{array}$ & Canada & Heart & $\begin{array}{l}\text { Aerobic and } \\
\text { strength training }\end{array}$ & $\begin{array}{l}\text { For } 8 \text { weeks, treadmill and cycle exercises were } \\
\text { performed at a heart rate equal to } 60-80 \% \mathrm{VO}_{2} \\
\text { peak for } 30-45 \mathrm{~min} \text {. In the final } 4 \text { weeks, } \\
\text { continuous aerobic training was performed } 3 \\
\text { days/week ( } 45 \text { min/session at a heart rate equal } \\
\text { to } 80 \% \mathrm{VO}_{2} \text { peak) and interval training was } \\
\text { performed } 2 \text { days/week. }\end{array}$ & 12 weeks \\
\hline $\begin{array}{l}\text { Hermann et al. } \\
(2011)\end{array}$ & Denmark & Heart & $\begin{array}{l}\text { High intensity } \\
\text { aerobic exercise }\end{array}$ & $\begin{array}{l}\text { After warming up, a } 42 \text {-min high intensity exercise } \\
\text { program followed, with interval blocks of } 4 \mathrm{~min} / 2 \\
\text { min/30 s according to } 80 \%, 85 \% \text { and } 90 \% \text { of } \mathrm{VO}_{2} \\
\text { peak and recovery periods of } 1 / 2 \text { min. Finally, } 10 \\
\text { min of staircase running up according to } 80 \% \text { of } \\
\text { peak } \mathrm{VO}_{2} \text { and recovery walking down according } \\
\text { to } 50 \% \text { peak } \mathrm{VO}_{2} \text {. }\end{array}$ & 2 months \\
\hline Juskowa et al. (2006) & Poland & Kidney & Physical exercise & 30 min per session. & $\begin{array}{l}4 \text { or } 5 \text { weeks post } \\
\text { transplantation }\end{array}$ \\
\hline Karelis et al. (2016) & Canada & Kidney & $\begin{array}{l}\text { Resistance } \\
\text { training }\end{array}$ & $\begin{array}{l}45-60 \text { min in-hospital RT program. The intensity } \\
\text { of the exercise training sessions was } \\
\text { approximately } 80 \% \text { of the } 1-\mathrm{RM} \text {. }\end{array}$ & 16 weeks \\
\hline Kouidi et al. (2013) & Greece & Kidney & $\begin{array}{l}\text { Aerobic and } \\
\text { strengthening }\end{array}$ & $\begin{array}{l}30-40 \text { min aerobic exercise programme followed } \\
\text { by } 10-30 \text { min of strengthening exercises. The } \\
\text { target intensity was scheduled to be close to the } \\
\text { anaerobic or ventilatory threshold ( } 50-75 \% \mathrm{VO}_{2} \\
\text { peak or } 65-85 \% \mathrm{HR} \text { max). }\end{array}$ & 6 months \\
\hline Langer at al. (2012) & Belgium & Lung & $\begin{array}{l}\text { Resistance } \\
\text { training }\end{array}$ & $\begin{array}{l}\text { Session lasted for about } 90 \text { min. Patients } \\
\text { performed } 3 \text { times } 8 \text { repetitions using leg press } \\
\text { equipment, with the initial load set at } 70 \% \text { of the } \\
\text { 1-RM. }\end{array}$ & 3 months \\
\hline Leasure et al. (1995) & USA & Kidney & Aerobic & $\begin{array}{l}\text { Completion times for the exercise sessions } \\
\text { progressed from } 30 \text { to } 60 \text { minutes: } 5 \text {-min warm-up } \\
\text { and a cool-down, an aerobic portion, and a } \\
\text { strengthening portion. }\end{array}$ & 12 weeks \\
\hline
\end{tabular}

TABLE 1 (Continued on next page) 


\begin{tabular}{|c|c|c|c|c|c|}
\hline Mitchell et al. (2003) & USA & Lung & $\begin{array}{l}\text { Resistance } \\
\text { training }\end{array}$ & $\begin{array}{l}\text { One set of variable resistance lumbar extensions } \\
\text { through a } 72 \text {-degree ROM with a weight load that } \\
\text { allowed } 15-20 \text { repetitions to volitional muscle } \\
\text { fatigue. }\end{array}$ & 6 months \\
\hline $\begin{array}{l}\text { Moya-Najera et al. } \\
(2017)\end{array}$ & Spain & Liver & $\begin{array}{l}\text { Aerobic and } \\
\text { resistance training }\end{array}$ & $\begin{array}{l}\text { During the first } 3 \text { months, patients had to perform } \\
3 \text { sets of } 25 \text { repetitions at a velocity of } 2 \text { seconds } \\
\text { for each concentric and eccentric contraction. } \\
\text { During the second } 3 \text {-month period, patients had to } \\
\text { perform } 3 \text { sets of } 15 \text { repetitions at a velocity of } 2 \\
\text { seconds for each concentric and eccentric } \\
\text { contraction. }\end{array}$ & 24 weeks \\
\hline Nytroen et al. (2012) & Norway & Heart & HIIT & $\begin{array}{l}\text { The HIIT-sessions consisted of } 10 \text { min warm-up, } \\
\text { followed by four } 4 \text {-min exercise bouts at } 85-95 \% \\
\text { of maximum heart rate (HR max), interposed by } 3 \\
\text { min active recovery. periods (Figure } 2 \text { ) } \\
\text { corresponding to } \sim 11-13 \text { on the Borg, } 6-20 \text { rated } \\
\text { perceived exertion (RPE) scale. }\end{array}$ & 24 weeks \\
\hline Painter et al. (2002) & USA & Kidney & $\begin{array}{l}\text { Cardiovascular } \\
\text { exercise (walking } \\
\text { or cycling) }\end{array}$ & $\begin{array}{l}\text { Frequency of at least } 4 \text { times per week; duration } \\
\text { that worked up to at least } 30 \text { min per session; and } \\
\text { an intensity that was initially } 60-65 \% \text { of maximal } \\
\text { heart rate, which was gradually (approximately } \\
\text { every } 2 \text { weeks) increased to } 75-80 \% \text { of maximal } \\
\text { heart rate. }\end{array}$ & 1 year \\
\hline $\begin{array}{l}\text { Pascoalino et al. } \\
\text { (2015) }\end{array}$ & Brazil & Heart & Exercise training & $\begin{array}{l}\text { Thrice-weekly exercise training program. } \\
\text { Supervised sessions consisted of } 5 \text { min of warm- } \\
\text { up, } 40 \text { min of endurance exercise at an intensity } \\
\text { of } 80 \% \text { of the respiratory compensation point and } \\
5 \text { min of cool-down. }\end{array}$ & 12 weeks \\
\hline $\begin{array}{l}\text { Pooranfar et al. } \\
\text { (2014) }\end{array}$ & Iran & Kidney & $\begin{array}{l}\text { Aerobic and } \\
\text { resistive } \\
\text { exercises }\end{array}$ & $\begin{array}{l}\text { Three } 60-90 \text {-min sessions per week. Aerobic } \\
\text { exercise on fixed bicycle or treadmill with } 40 \%- \\
70 \% \text { maximum heart rate intensity and resistive } \\
\text { exercise with } 45 \%-65 \% \text { of maximum frequency. }\end{array}$ & 10 weeks \\
\hline Riess et al. (2014) & Canada & Kidney & $\begin{array}{l}\text { Endurance and } \\
\text { strength training }\end{array}$ & $\begin{array}{l}\text { Endurance ( } 3 \text { days/week) and strength training ( } 2 \\
\text { days/week). Endurance training was performed on } \\
\text { a cycle ergometer and treadmill at } 60 \%-80 \% \mathrm{VO}_{2} \\
\text { peak for } 30-60 \mathrm{~min} / \mathrm{session} \text {. Lower extremity } \\
\text { strength training was performed at } 50 \% 1-\mathrm{RM} \text { for } \\
2 \text { sets of } 10-15 \text { repetitions. The intensity } \\
\text { increased by } 5 \%-10 \% \text { when } 2 \text { sets of } 15 \\
\text { repetitions were performed. }\end{array}$ & 12 weeks \\
\hline Shakoor et al. (2016) & Iran & Kidney & $\begin{array}{l}\text { Aerobic and } \\
\text { anaerobic }\end{array}$ & $\begin{array}{l}\text { Three sessions per week for } 60-90 \mathrm{~min} \text {. Each } \\
\text { session included a } 15 \text {-min warm-up, } 20 \text { min of } \\
\text { aerobic exercise, } 20 \text { min of resistance exercise, } \\
\text { and a } 10 \text {-min cool-down including running with a } \\
\text { slow pace followed by stretching and light } \\
\text { exercises. }\end{array}$ & 10 weeks \\
\hline $\begin{array}{l}\text { Tzvetanov et al. } \\
\text { (2014) }\end{array}$ & USA & Kidney & $\begin{array}{l}\text { Resistance } \\
\text { training }\end{array}$ & $\begin{array}{l}\text { Individual physical training using low-impact, low- } \\
\text { repetition, resistance-based weight training with } \\
\text { two 1-hour sessions each week. }\end{array}$ & 1 year \\
\hline
\end{tabular}

1-RM: one-repetition maximum, $\mathrm{HR}$ : heart rate, $\mathrm{VO}_{2}$ peak: highest value of $\mathrm{VO}_{2}$ attained on a particular exercise test, RT: resistance training, ROM: range of motion, $\mathrm{HITT}$ : highintensity interval training, RPE: rating of perceived exertion

TAB LE 1 Characteristics of the included studies 


\begin{tabular}{|c|c|c|c|c|c|c|c|c|c|c|c|c|c|c|c|c|c|c|c|c|}
\hline Study & 1 & 2 & 3 & 4 & 5 & 6 & $7 \mathbf{a}$ & $7 b$ & 8 & 9 & 10 & 11 & 12 & 13 & $14 a$ & 14b & 15 & $16 a$ & $16 b$ & Score \\
\hline Basha et al. (2015) & (-) & (-) & : & (2) & (-) & $: 2$ & (-) & (-) & (-) & (-) & (:) & : & (*) & (-) & (:) & $: 0$ & (-) & (:) & (:) & $9 / 19$ \\
\hline Bernadi et al. (2007) & (:) & : $:$ & : : & : & (:) & : & (:) & (-) & : & (-); & : $:$ & : $:$ & (-) & (-) & : & : & () & : & (:) & $6 / 19$ \\
\hline Braith et al. (2008) & (): & () & (2) & (2) & (2) & (2) & (2) & () & (2) & (:) & (2) & (*) & (): & (:) & () & (-) & () & (:) & (:) & $4 / 19$ \\
\hline Eatemadololama et al. (2017) & (2) & (-) & (*) & (:) & (2) & (:) & (2) & (-) & (2) & : $:$ & (*) & (2) & (2) & (-) & (2) & () & (2) & : $:$ & 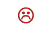 & $4 / 19$ \\
\hline Greenwood et al. (2015) & (2) & (:) & () & (:) & (:) & (2) & (-) & (2) & (2) & (2) & (:) & (2) & (:) & (:) & (2) & (:) & (2) & (2) & (:) & $14 / 19$ \\
\hline Haykowsky et al. (2009) & (:) & : $:$ & : : & : $:$ & (:) & : $:$ & : & (:) & : $:$ & : $:$ & (:) & (-) & : & (-) & (:) & (:) & (:) & : : & (:) & $4 / 19$ \\
\hline Hermann et al. (2011) & (:) & (:) & : & 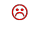 & : & (:) & (:) & $:$ & : & : & : & (-) & (-) & (-) & (-) & $:$ & (:) & : & (:) & $6 / 19$ \\
\hline Juskowa et al. (2006) & () & (-) & (:) & () & (:) & : $:$ & (:) & (:) & (:) & : $:$ & (:) & : $:$ & (:) & (:) & (:) & (:) & () & (:) & () & $1 / 19$ \\
\hline Karelis et al. (2016) & (:) & (-) & : $:$ & (:) & (:) & (:) & (2) & : $:$ & () & (2) & (:) & (2) & (): & (:) & (2) & (:) & (-) & (2): & () & $12 / 19$ \\
\hline Kouidi et al. (2013) & (:) & () & (:) & () & (:) & : $:$ & (:) & (:) & : $:$ & : $:$ & (:) & : $:$ & (:) & (-) & (:) & (-) & (:) & : : & () & $7 / 19$ \\
\hline Langer at al. (2012) & (-) & () & () & (2) & (2) & (:) & () & () & () & (2) & () & (2) & (2) & (-) & (): & () & () & () & (2) & $8 / 19$ \\
\hline Leasure et al. (1995) & (:) & () & : $:$ & 웅 & : $:$ & (:) & (:) & (:) & : $:$ & : $:$ & (:) & : $:$ & (-) & : $:$ & (:) & (:) & () & : $:$ & (2) & $4 / 19$ \\
\hline Mitchell et al. (2003) & (:) & (-) & () & () & (2) & (2) & () & () & (-) & (2) & (2) & () & () & (-) & (2) & () & (:) & () & (2) & $5 / 19$ \\
\hline Moya-Najera et al. (2017) & (:) & (:) & : & (-) & (:) & : & (-) & (:) & : & : $:$ & : $:$ & (:) & (2) & (:) & (2) & : & (:) & : & (:) & $9 / 19$ \\
\hline Nytroen et al. (2012) & (-) & (-) & (-) & (-) & : & (:) & (:) & (:) & (8) & : 8 & : & : & (:) & (-) & (-) & (-) & : & (:) & (:) & $7 / 19$ \\
\hline Painter et al. (2002) & : $:$ & : $:$ & (-) & : $:$ & (:) & (:) & : $:$ & (:) & : & : : & (*) & : $:$ & (-) & (-): & (:) & (:) & (:) & (-) & (:) & $10 / 19$ \\
\hline Pascoalino et al. (2015) & (-) & : & : & (:) & 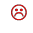 & : & : & : & : $:$ & (-) & : & : & (:) & (-) & : & (:) & (:) & : & (:) & $3 / 19$ \\
\hline Pooranfar et al. (2014) & (-) & () & : $:$ & (:) & (:) & : $:$ & (웅 & () & : $:$ & : $: 1$ & (:) & () & () & (-) & () & () & () & (:) & () & $5 / 19$ \\
\hline Riess et al. (2014) & (-) & (-) & : & (:) & : & : & (-) & (-) & : & $:$ & : & : & : & (-) & (-) & (:) & (:) & : & (:) & $7 / 19$ \\
\hline Shakoor et al. (2016) & () & () & () & () & (:) & () & (웅 & () & () & () & (2) & () & (:) & (-) & : $:$ & (-) & (2) & () & () & $3 / 19$ \\
\hline Tzvetanov et al. (2014) & (:) & : & (:) & (:) & : & : $:$ & : & : & : & $: 8$ & (:) & 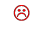 & (:) & : & (:) & () & () & : & (:) & $5 / 19$ \\
\hline Average score & & & & & & & & & & & & & & & & & & & & 6.0 \\
\hline
\end{tabular}

Yes: (-), No: :

TABLE 2 Consensus on exercise reporting template items of articles examining the effects of exercise training programs in SOT recipients

\begin{tabular}{|c|c|c|}
\hline \# & Question & $\mathrm{n}(\%)$ \\
\hline 1 & Type of exercise equipment & $15(71)$ \\
\hline 2 & Qualifications & $9(43)$ \\
\hline 3 & Individually/in a group & $3(14)$ \\
\hline 4 & Supervised/unsupervised & $14(67)$ \\
\hline 5 & Adherence to exercise & $6(29)$ \\
\hline 6 & Motivation strategies & $3(14)$ \\
\hline $7 a$ & Decision rules for exercise progression & $8(38)$ \\
\hline $7 b$ & Description of exercise progression & $9(43)$ \\
\hline 8 & Description of each exercise to enable replication & $2(10)$ \\
\hline 9 & Home program component & $4(19)$ \\
\hline 10 & Non-exercise components & $4(19)$ \\
\hline 11 & Type and number of adverse events & $3(14)$ \\
\hline 12 & Setting in which the exercises are performed & $10(48)$ \\
\hline 13 & Detailed description of the exercise intervention & $18(86)$ \\
\hline $14 a$ & Generic/tailored & $12(57)$ \\
\hline $14 \mathrm{~b}$ & Detailed description of how exercises are tailored & $9(43)$ \\
\hline 15 & Decision rule for determining the starting level & $6(29)$ \\
\hline $16 a$ & Description of how adherence is measured & $2(10)$ \\
\hline $16 \mathrm{~b}$ & Intervention delivered as planned & $3(14)$ \\
\hline
\end{tabular}

TAB LE 3 Percentage of articles that describe items of Consensus on Exercise Reporting Template 


\section{APPENDIX 1}

\section{1 | Ovid Medline (All) Search Strategy}

1. Physical activity.ti,ab,kf.

2. exercise.ti,ab,kf.

3. exp Exercise/ or exp Exercise Therapy/

4. Physical Fitness/

5. physical fitness.ti,ab,kf.

6. exp Organ Transplantation/

7. ((organ or heart or kidney or pancreas or liver or lung) adj (transplant or transplantation or transplanted or transplants)).ti,ab,kf.

8. 6 or 7

9. 1 or 2 or 3 or 4 or 5

10. 8 and 9

11. randomized controlled trial.pt.

12. controlled clinical trial.pt.

13. randomi?ed.ab.

14. placebo.ab.

15. drug therapy.fs.

16. randomly.ab.

17. trial.ab.

18. groups.ab.

19. or/11-18

20. exp animals/ not humans.sh.

21. 19 not 20

22. 8 and 21 and $9</$ li $>$ 